\title{
A CULTURA VISUAL DA MARUJADA: SENTIDOS E SIGNIFICADOS DAS PRÁTICAS CULTURAIS DA JUVENTUDE BRAGANTINA-PA: O ESTADO DA ARTE (2014-2018)
}

\author{
THE VISUAL CULTURE OF MARUJADA: MEANINGS AND MEANINGS \\ OF PRACTICES CULTURALS OF YOUTH BRAGANTINA-PA:
}

THE STATE OF THE ART (2014-2018)

\section{Rita de Cássia Cabral Rodrigues de França \\ EA/UFPA}

\section{Resumo}

Este estudo surgiu a partir das instigações havidas na disciplina de doutorado: Concepções e Procedimentos Metodológicos em Artes. Tem por objetivo mapear as produções acadêmicas que tangenciem nossa pesquisa. Os descritores sobre cultura visual, juventude e diversidade cultural, produzidas em Artes nas universidades federais e nos periódicos. A metodologia é de cunho qualitativo descritivo, estruturada por meio da revisão bibliográfica: Cultura visual com Hernández (2007); com Barbosa (2002, 2009) para o ensino de arte; está baseado nos estudos de análise de estado da arte com base em Ferreira (2002); Coelho, Santos e Silva (2014) e Müller (2015). Nossas fontes de investigação são oriundas do banco de teses e dissertações da Fundação Coordenação de Aperfeiçoamento de Pessoal de Nível Superior (CAPES), Associação Nacional de Pesquisadores em Artes Plásticas - ANPAP, do - Congresso Nacional da Federação dos Arte/ Educadores do Brasil-CONFAEB. Resultados iniciais: alguns trabalhos se convergem com a tese e outros divergem, principalmente, porque tratamos da cultura visual presente na prática cultural da marujada pela juventude bragantina e a sua reverberação na cultura da escola.

\section{Palavras-chave:}

Cultura Visual; Cultura Afro-brasileira; Juventude; Marujada.

\section{Abstract}

This study arose from the instigations in the doctoraldiscipline: Conceptions and Methodological Procedures in Arts. It aims to map the academic productions that touch our research. Descriptors on visual culture, youth and cultural diversity, produced in Arts at federal universities and in periodicals. The methodology is of a descriptive qualitative nature, structured through the bibliographic review: Visual culture with Hernández (2007); with Barbosa (2002, 2009) for teaching art, it is based on state of the art analysis studies based on Ferreira (2002); Coelho, Santos e Silva (2014) and Müller (2015). Our research sources come from the thesis and dissertation database of the Coordination Foundation for the Improvement of Higher Education Personnel (CAPES), National Association of Researchers in Plastic Arts - ANPAP, of the - National Congress of the Federation of Art I Educators of Brazil-CONFAEB . Initial results: some works converge with the thesis and others diverge, mainly because we deal with the visual culture present in the cultural practice of marujada by Bragantine youth and its reverberation in the school culture.

Keywords:

Visual Culture; Afro-Brazilian culture;

Youth; Marujada 


\section{INTRODUÇÃO}

Tantas palavras escritas desde o princípio, tantos traços, tantos sinais, tantas pinturas, tanta necessidade de explicar e entender, e ao mesmo tempo tanta dificuldade porque ainda não acabamos de explicar e ainda não conseguimos entender. (SARAMAGO, 2000, p. 21).

O fragmento que dá abertura ao texto desvela que o ser humano está em uma busca incessante de decifrar e compreender o desconhecido. No campo da pesquisa não é diferente, faz-se necessário investigar, conhecer e entender o conteúdo já produzido acerca de um certo objeto, daí a necessidade do levantamento bibliográfico ou estado do conhecimento. Posto isto, o interesse pelo objeto de pesquisa, deste estudo, surgiu a partir das instigações havidas na disciplina de doutorado: Concepções e Procedimentos Metodológicos em Artes, cujo objetivo foi o de fomentar e aprofundar conhecimentos sobre os diversos procedimentos metodológicos de pesquisa, com o propósito de contribuir para a formação dos alunos, de forma prática e consubstanciada, levando-os a compreenderem e para as possíveis escolhas de caminhos metodológicos de suas teses.

Este artigo é parte inicial da pesquisa de tese ${ }^{1}$ intitulada: A cultura visual da marujada: sentidos e significados das práticas culturais da juventude bragantina-PA: o estado da arte (2014-2018). Surgiu da reflexão acerca das diversas teorias metodológicas e da necessidade de delimitarmos o objeto de nossa pesquisa, neste estudo em específico: os sentidos e significados da juventude bragantina sobre a cultura visual presente na marujada. Sem perder de vista o diálogo com a educação, para as relações étnico-raciais, na perspectiva da Lei $n^{\circ}$. 10.639/2003. Tal lei engendra uma nova dinâmica nas escolas e elege a África como uma das matrizes das instituições nacionais e promove a (re)orientação do currículo escolar com a inclusão de um conteúdo inédito na educação básica, pensando um currículo na perspectiva da subversão do poder colonial.

Compreende-se que a Lei $\mathrm{n}^{\circ}$ 10.634/2003 introduz no currículo da educação básica o ensino da História e da cultura afro-brasileira e africana. Entretanto, apesar da festividade da marujada movimentar toda a região bragantina e ter valor cultural, por ser uma celebração cultural/religiosa dos afrodescendentes e transgrediu algumas imposições religiosas no passado para poder demarcar sua história de origem, é instigante investigar se ela é valorizada, se é reconhecida pela juventude e professores do ensino de Arte como herança cultural do povo negro e, quiçá, faça parte do currículo e da cultura da escola.

A Marujada é uma manifestação cultural imaterial do estado do Pará, tombada desde 2009. Vem das classes populares, de origem inclusive de Irmandade de negros. Pela concepção de Bourdieu (2007a), quando analisa os sujeitos e as práticas culturais, de acordo com uma classificação elaborada por ele, esse tipo de manifestação atende ao gosto da camada popular, logo, pode-se entender que ela é uma manifestação cultural de menor valor e interesse, inclusive pela escola que tende a invisibilizar a história e cultura do negro no currículo, subsumindo-as a uma contextualização do exótico, obliterando, consequentemente, a valorização e reciprocidade entre culturas.

Outra questão de análise é se essa cultura visual tem sua inserção no currículo escolar do Ensino de Arte, por meio da cultura da escola e que relações e valorizações a juventude faz do conhecimento da cultura visual e a apropriação do seu patrimônio cultural, sendo ele de matriz africana, considerando que esses são fatores indispensáveis no processo de preservação sustentável desses bens culturais, assim como no fortalecimento dos sentimentos de identidade e cidadania da juventude afrobrasileira. Diante disto, nos indagamos da presença dessa manifestação cultural, por meio da cultura visual no currículo escolar do Ensino de Artes Visuais, e como ela é inserida na cultura da escola bragantina, rompendo com currículo dominante, dando a conhecer outras histórias e culturas de outros povos não brancos.

Diante de tais ponderações, nos questionamos: que produções acadêmicas sobre cultura visual, ensino de Artes Visuais e diversidade cultural, têm sido produzidas em Artes nas universidades federais e periódicos? O que revelam as produções acadêmicas sobre cultura visual, ensino de Artes Visuais e diversidade cultural? Que referenciais teórico-metodológicos têm sido utilizados nessas produções? Que resultados têm apresentado essas produções? Este estudo tem por objetivo mapear as produções acadêmicas sobre cultura visual, 
ensino de Artes Visuais e diversidade cultural, produzidas em Artes nas universidades federais e nos periódicos, no período de 2014-2018.

Apresenta nos passos metodológicos iniciais uma abordagem qualitativa, com aplicação da pesquisa bibliográfica: para cultura visual com Hernández (2007); e com Barbosa (2002, 2009) para o ensino de arte. A metodologia utilizada está baseada nos estudos de análise de estado da arte, com base em Ferreira (2002); Coelho, Santos e Silva (2014) e Müller (2015). Esta incursão encontrase delimitada, temporalmente, ao período que compreende os anos de 2014 a 2018, tal recorte não é arbitrário: tem a ver com os cinco anos do marco legal do título da marujada bragantina como Patrimônio imaterial do Estado do Pará.

Os estudos denominados estado da arte, segundo Ferreira (2002), mostra que para essa metodologia faz-se o levantamento de determinadas produções acadêmicas, a fim de se obter um caráter de inventário descritivo, buscando a verificação do conhecimento produzido em um recorte temporal por algum motivo específico:

[...] o desafio de mapear e de discutir certa produção acadêmica em diferentes campos do conhecimento, tentando responder que aspectos e dimensões vêm sendo destacados e privilegiados em diferentes épocas e lugares, de que formas e em que condições têm sido produzidas certas dissertações de mestrado, teses de doutorado, publicações em periódicos e comunicações em anais de congressos e de seminários (FERREIRA, 2002, p. 258).

O Estado da Arte se constitui em um método que apresenta uma investigação profunda acerca do que foi e vem sendo discutido, além de trazer à tona e dar visibilidade às produções mapeadas, possibilitando uma constante complementação conforme assevera Müller (2015, p. 168): além de ser um método adotado e utilizado para dar visibilidade e abrangência da produção em diversas áreas, entende-se que ele deve ser usado com constância e regularidade, visto sua importância para o mapeamento dos diferentes campos de conhecimento, e por possibilitar a permanente atualização dos dados.

Para orientar a compilação dos textos e com o objetivo de sistematizar a produção do conhecimento sobre o tema Cultura Visual e sentidos e significados da juventude bragantina, sobre a prática cultural da marujada e a possível analogia ou discrepância com o objeto de deste estudo, definimos os seguintes descritores: Cultura Visual, Ensino de Artes Visuais e diversidade cultural.

Foram selecionados artigos da Coordenação de Aperfeiçoamento de Pessoal de Nível SuperiorCAPES, Associação Nacional de Pesquisadores em Artes Plásticas - ANPAP², do - Congresso Nacional da Federação dos Arte/Educadores do BrasilCONFAEB, e de outras revistas, por apresentarem correlação com o tema cultura visual, sentidos e significados da juventude sobre as práticas culturais. As pesquisas foram apresentadas e sistematizadas em grupos.

Para facilitar o estudo sobre a produção acadêmica entre 2014 e 2018, citamos conclusões e fazermos um comparativo naquilo que se aproximam ou não do objeto deste estudo, optamos por levantar um grupo para cada descritor, destacando na sistematização o ano, título do artigo, o autor, a metodologia e conclusão. o primeiro grupo trata dos artigos sobre Cultura Visual; o segundo do Ensino de Artes Visuais; e, por último, o grupo de diversidade cultural. Com essa forma de abordagem, apresentamos insumos que serviram como parâmetros epistemológicos e metodológicos para subsidiar, do ponto de vista acadêmico, o nosso objeto de estudo.

O presente estudo tem como objeto de pesquisa os sentidos e significados da juventude sobre a cultura visual presentes nas práticas culturais da marujada, já dito antes. A festa da marujada acontece na região bragantina ${ }^{3}$, também conhecida como região do salgado, em devoção a São Benedito, santo preto muito cultuado nessa região paraense. Esse festejo movimenta vários seguimentos em diversos espaços, por onde circulam devotos e suas homenagens, os turistas encantados com o festejo, as marujas e marujos ${ }^{4}$ com o colorido típicos de suas indumentárias, o chapéu, é a coroa com um arco-íris vibrante de fitas, o estandarte, enfeitado com o colorido ao redor, e, no centro, a imagem emblemática de São Benedito, vai à frente anunciando o cortejo da procissão do "santo preto", uma cultura visual que me deixa ver pela janela do meu olhar a pujança dos guerreiros (marujas e marujos) presente na celebração, comunica no contemporâneo a cultura da região de origem na ancestralidade diaspórica. 


\section{O PRIMEIRO GRUPO DE INVESTIGAÇÃO: CULTURA VISUAL}

A pesquisa de Brito (2014) - Abordagem Reflexiva Sobre a Cultura Visual como Expressão da Comunicação Contemporânea, se converge com o objeto desse artigo, por entender a cultura visual na contemporaneidade como mediador de valores culturais, construídos por homens e mulheres com dotes estéticos. A autora utilizou como referencial teórico, para uma melhor reflexão, estudos a partir de: Barbosa (1998; 2002; 2005), Baxandal (2006), Buoro (2002), Hernández (2000) e Manguel (2006). Objetiva apresentar questões que buscam evidenciar o mundo imagético, as representações sociais e culturais por meio da cultura visual.

O trabalho Desafio de Ensinar Arte: cultura visual e novos olhares para o trabalho docente de Silva (2015), é outro que desvela similitude com o objeto deste estudo. A autora compreende a cultura visual e as relações entre as posições subjetivas e as práticas culturais e sociais do olhar, e a influência na reflexão na forma de valorizar ou não às diversas culturas. Utilizou como referencial teórico, para abordar cultura visual, Hernández (2000; 2007); o ensino de arte com Barbosa (2005); apropriou-se também da legislação da educação brasileira, tais como os Parâmetros Curriculares Nacionais (PCN), e a Lei no 9.394/96 de Diretrizes e Base da Educação.

Silva (2015), por meio de Hernández (2007), conceitua cultura visual, mostra porque é fulcral compreender que pela janela do olhar do outro são construídas narrativas que nos é dado a serem interpretadas visualmente, vejamos:

\begin{abstract}
A expressão cultura visual refere-se a uma diversidade de práticas e interpretações críticas em torno das relações entre as posições subjetivas e as práticas culturais e sociais do olhar [...] do movimento cultural que orienta a reflexão e as práticas relacionadas a maneiras de ver e de visualizar as representações culturais e, em particular, refiro-me às maneiras subjetivas e intrasubjetivas de ver o mundo e a si mesmo (HERNÁNDEZ, 2007, p. 22).
\end{abstract}

Pensando nessas maneiras subjetivas e intrasubjetivas de ver e interpretar o mundo e a si mesmo, nos remetemos a Dussel (2002), o eurocentrismo para ele consiste em estabelecer como universalidade abstrata humana, em geral, ocasiões, coisas, relações, saberes da particularidade europeia, como a cultura, a civilização, a filosofia, a subjetividade, sendo valorizadas e reproduzidas como as ideais de mundo, logo, perde o valor e deve ser eliminado ou dizimado tudo que se distanciar do modelo balizar de civilização "o europeu". A história e a cultura sobre os países colonizados são contadas e transmitidas ainda na racionalidade eurocêntrica e, essa prática reverbera no currículo da educação básica.

Já a pesquisa Cultura Visual e Construções de Gênero: reflexões e experiências em sala de aula, de Abreu, Ospina e Monteles (2016) se propõem subverter a ordem, a usar as visualidades como dispositivos para desconstruir as noções de identidade fixa. A abordagem metodológica que adotaram caminhou em direção oposta às metodologias estáticas. Na metodologia, empregam abordagem da pedagogia crítica (GIROUX, 2011), Victório Filho (2008); Martins \& Tourinho (2013); Foucault (1988). Os autores indicam um percurso com ênfase na flexibilidade, baseada em estratégias que valorizam a construção de debates críticos, bem como narrativas que levam em consideração o alunado e seus contextos sociais, culturais e suas identidades de gênero.

A pesquisa Tiana, a primeira princesa negra da Disney: olhares analíticos construídos junto à cultura visual traz a primeira princesa negra da Disney, o estudo é de Baliscei, Calsa, Stein (2017), significativo para a construção da identidade negra brasileira. Eles utilizam, teoricamente, pesquisas da área da sociologia (ARIÈS, 2012; SARMENTO, 2005) e educação (MOMO, 2008; CUNHA, 2011; 2014). O estudo tem contribuído para problematizar e desestabilizar essa visão "romântica" e "cristalizada" de infância, explicando-a como uma invenção da sociedade moderna. Como resultado, nos últimos minutos do filme, Tiana e Naveen encontram o "felizes para sempre" no trabalho, com o restaurante, o que parece confirmar e reforçar os estereótipos de servidão para negros e negras e de deleite e consumo para brancos e brancas.

Com a Lei n. 10. 639/2003, implementada nas escolas, espera-se desconstruir esses estereótipos, pois com a sanção dessa Lei, o Brasil assume a responsabilidade de descolonizar 0 
currículo escolar, dar voz e valorizar a cultura dos povos tidos como subalternos. Para tal intento, fora preciso formações para professores da Educação Básica, de forma que se apropriassem do que trata o escopo da legislação sobre a questão étnica-racial, já que a ideia central dessa lei indicava que o ensino de conteúdos étnicoraciais deveria ser ministrado em todo o currículo escolar dos Ensinos Fundamental e Médio, em específico pelas disciplinas de História, Ensino de Arte e Literatura.

O estudo de título: Cultura Visual e Arte/Educação Baseada na Comunidade: Interlocuções com a Educação do Campo de Freitas e Silva (2018), apesar de abordar a educação do campo, se afina com o nosso estudo quando aborda temas como a interculturalidade, a cultura visual e identidade. Eles apresentam a proposta de construir uma política que assente a grande diversidade das populações, promovendo Oficinas de Artes para bordar e pensar: interculturalidade e identidade no ensino de artes visuais. A metodologia é de cunho qualitativo, os teóricos Hernández (2007); Azevedo e Santos (2016) e as Diretrizes Operacionais para a Educação Básica das Escolas do Campo (2002). Como resultado, as análises desse estudo revelam que é possível o diálogo entre as referidas áreas do conhecimento da cultura visual e da educação do campo, pois ambas defendem a justiça social, uma educação emancipadora e crítica.

Nesse primeiro inventário de estudos elencados, podemos afirmar que os estudos trazem no cerne a discussão em abordagem distintas a cultura visual, e a partir dela a percepção do olhar sobre o que nos deixam ver e as diversas interpretações, identidade e os estereótipos reproduzidas sobre o negro. Em sua maioria apresentam a metodologia de cunho qualitativo e o autor Hernández (2000 e 2007), para o conceito de cultura visual. Alguns trabalhos se convergem com a tese e outros divergem, principalmente porque tratamos da cultura visual presente na prática cultural da marujada pela juventude bragantina. Entretanto, as pesquisas citadas em comum indicam a importância da cultura visual para vermos que "as distinções e desigualdades raciais são contundentes, facilmente visíveis e de graves consequências para a população afrobrasileira e para o país como um todo" (HERINGER, 2002, p. 58).

\section{O SEGUNDO GRUPO DE INVESTIGAÇÃO: ENSINO DE ARTES VISUAIS.}

O estudo de Cardoso Junior (2017) - Ensino de Artes Visuais em Perspectiva Eurocêntrica: um estudo de caso no Colégio Pedro /I - tem como objeto de estudo Ensino de Artes Visuais em perspectiva eurocêntrica, traz a proposta de pensar a naturalização dos conhecimentos escolares eurocêntricos no ensino de Artes Visuais, parte das teorizações da educação intercultural crítica e busca articular o questionamento e a desconstrução da monoculturalidade com a promoção da interculturalidade na educação escolar. A metodologia não foi citada. Dialoga com os autores Catherine Walsh (2009a; 2009b), Candau (2013), que aborda a educação intercultural como parte da afirmação da diferença como riqueza. Sobre o conceito de ecologia de saberes com Boaventura de Sousa Santos (2008), a preocupação com a diversidade cultural e a herança artística e estética dos/as alunos/as com Barbosa, (1998; 2002; 2009; 2010) e Martins, Tourinho (2009; 2010).

Para o autor Cardoso Júnior (2017), a educação intercultural crítica é uma perspectiva em construção no campo educacional brasileiro e a sua consolidação no ensino de Artes Visuais passa pelo estabelecimento de diálogos horizontais, que articulem igualdade e diferença entre concepções distintas de arte e cultura, necessitando-se, para tanto, superar qualquer relação de saberes/ conhecimentos que configurem hierarquias essencializadas para a sua construção (complexa) na educação escolar.

O trabalho Ensino de Arte e os Saberes Escolares: a experiência de uma comunidade quilombola, de Silva e Araújo (2014), desvela a discussão sobre o ensino de artes, a escola e a comunidade quilombola, na construção de um processo de ensino de arte baseados nas relações de valorização da cultura e de saberes. A abordagem utilizada foi qualitativa de cunho etnográfico. Os dados foram coletados por meio de entrevista semiestruturada e observações, tendo como interlocutores da pesquisa os professores da comunidade que lecionavam a disciplina de Arte nas diversas modalidades de ensino. E segundo Silva e Araújo (2014) afirmam: "[...] contamos também com a contribuição das alunas-artesãs 
matriculadas no ensino regular" (p. 522). As pesquisas sobre o Ensino de Arte, conforme Barbosa (2002), Buoro (2003), Hernández (2000), entre outros autores que abordam com visões distintas essa temática, apontam para uma maior compreensão da Arte na Educação, em particular para o papel da cultura visual no campo educacional (SILVA E ARA: JO, 2014).

O trabalho com o título Formação de Professores para o Ensino de Artes Visuais: uma experiência de estágio com a fotografia por meio da leitura de imagem, de Mendes et. al. (2015), teve como referencial teórico Rossi (2009); Barbosa (1998). A pesquisa se desenvolve a partir das experiências vivenciadas durante o Estágio Curricular Supervisionado do curso de Artes Visuais da Universidade Estadual de Maringá (UEM). Nas oficinas, as falas eram seguidas das imagens utilizadas durante a realização das ações educativas, inclusive na apresentação dos resultados e análises. As oficinas foram desenvolvidas em períodos do contra turno dos alunos. Mendes et. al. (2015) cita Fischer, nossa própria existência não nos basta, vivemos em uma busca constante por completude e é na arte que obtemos as condições necessárias para nos constituirmos como indivíduos, "a arte é necessária para que o homem se torne capaz de conhecer e mudar o mundo" (FISCHER, 1987, p. 20).

Silva e Silva (2018), Oficinas de Artes para bordar e pensar: interculturalidade e identidade no ensino de artes visuais, em tal trabalho pelo viés do bordado, trabalham temas como interculturalidade e identidades dos sujeitos no ensino de Artes Visuais. A experiência de apreciar e vivenciar a arte articulada à realidade do aluno promove o ensino de artes visuais como um espaço de educação intercultural, um caminho possível para a alteridade. A metodologia parte de uma pesquisa-ação qualitativa e fenomenológica. Possui o intuito de construir reflexões narrativas em torno de uma experiência com alunos do primeiro ao quinto ano do ensino fundamental.

A pesquisa de título Experiências de ensinar/ aprender no contexto dos estágios em Artes Visuais, de Magalhães (2016), aborda o ensinar/ aprender no processo de formação docente. Metodologicamente, é pesquisa de cunho qualitativo, tem como referencial teórico, entre outros, Penna (1994), Richter (2008). Os resultados possibilitaram inferir que o acesso às manifestações artísticas/culturais, local/ regional, pela maioria dos estudantes/estagiários e professores de Artes Visuais das escolas (campos de estágio) é incipiente, revelando em seus planejamentos de ensino uma visão europeia do campo.

Comrelaçãoaostrabalhosinventariadosnosegundo grupo de investigação, Ensino de Artes Visuais, apresentam na maioria a metodologia qualitativa bibliográfica: uma de cunho etnográfico. A Lei nº 10.639/2003 não foi diretamente abordada em nenhum no ensino de Artes Visuais, apesar da Lei n 9.394 de 1996 de Diretrizes e Bases Nacionais da Educação brasileira determinar que a História e a Cultura afro-brasileira e africana devem ser inseridas nos currículos das disciplinas de História, Língua Portuguesa e Ensino de Arte e na formação de professores. Os resultados do estudo de Magalhães (2016) aponta que no processo de ensinar/aprender em arte na formação inicial, o currículo prevalece monocultural desconsidera a diversidade dos alunos nas salas de aulas. Porém, em outra perspectiva, a questão que desvelamos defende que em alguns estudos o ensino de Artes Visuais tem relevância para trabalhar no currículo as questões candentes sobre as relações raciais, como raça, racismo, preconceito e discriminação, como pensado por Silva e Silva (2018), o ensino de arte é o lugar de educação intercultural, um caminho possível para a alteridade, compreendese o processo de ensino de arte baseados nas relações e respeito à diversidade cultural e saberes locais como a marujada bragantina.

\section{O TERCEIRO GRUPO DE INVESTIGAÇÃO: DIVERSIDADE CULTURAL}

Artigos sobre diversidade cultural. Em consonância com o nosso estudo, apresentamos o trabalho da autora Cerutti et. al. (2014), 0 Agente Cultural: Estudos e Práticas Étnicos Culturais em Espaços Socioeducativos, que tem como contexto da pesquisa o ensino médio. Os autores consideram que, embora as temáticas africanizadas e povos indígenas sejam importantes nas Metas do Plano Municipal de Cultura/PMC, são poucas as citadas nos projetos Fundo Municipal de Investimentos Culturais/ FMIC. Na pesquisa-ação na escola, foi observado 
no ensino médio alunos com pouco conhecimento e alguns estereótipos sobre os povos indígenas. 0 professor tem dificuldades com o tema, problema que reverbera na educação básica.

A juventude é considerada como sujeitos históricoculturais, com capital social, experiências, aprendizagens e vivências que podem se constituir como elementos de construção coletiva de identidades e de projetos de vida como assevera as Diretrizes Curriculares Nacionais da Educação Básica (BRASIL, 2013):

\begin{abstract}
A juventude como condição sócio-históricocultural de uma categoria de sujeitos que necessita ser considerada em suas múltiplas dimensões, com especificidades próprias que não estão restritas às dimensões biológica e etária, mas que se encontram articuladas com uma multiplicidade de atravessamentos sociais e culturais, produzindo múltiplas culturas juvenis ou muitas juventudes (BRASIL, 2013, p. 155).
\end{abstract}

Nessa mesma perspectiva, Dayrell (2009) advoga que a juventude é uma construção social iniciada na adolescência. Momento de grandes transformações biológicas, psicológicas, de integração social e conflitos de formação identitária. A realidade sócio-histórica desses sujeitos apresenta uma diversidade de etnias, valores, posições religiosas, social e cultural. A partir dessa visão, a atenção deve ser voltada para a construção de uma escola que incorpore a cultura própria da juventude que a compõe. Sugere-se, também, que a escola média propicie opções para os estudantes, abrindo-se para a diversidade, ao mesmo tempo em que se persegue uma escola promotora de culturas próprias do interesse da juventude, evitando a evasão escolar.

O trabalho de Silva (2015), As Práticas Educativas no Cotidiano da Marujada: uma análise epistemológica dos saberes populares e sua importância para o processo educativo, trata de cultura popular como a marujada. Desvela em seu trabalho, como principais bases teóricas para fundamentar essa discussão, os seguintes autores: Brandão (2010), Santos (2002), Morin (2000), Dussel (1994), Geertz (2008) e Oliveira (2007). Como caminho metodológico, utiliza-se apenas de pesquisas bibliográficas por se tratar de uma pesquisa em andamento e sem, ainda, dados de campo. Resultados, em virtude dessa negação da ciência aos saberes populares, a autora acredita na defesa de uma epistemologia que enxergue os saberes populares como válidos direcionados à Marujada como constructo social, cultural e de práticas educativas que corroboram para o "saber-fazer" incluídos num processo de ensino e aprendizagem.

Já a pesquisa de Gomes (2016), A experiência na formação de professores a partir da temática afrodescendente, traz a Lei de Diretrizes e Base Nacional no 9.394/1996, "que asseguram o direito à igualdade de condições de vida e de cidadania, assim como garantem igual direito às histórias e culturas que compõem a nação brasileira, além do direito de acesso às diferentes fontes da cultura nacional a todos brasileiros" (BRASIL, 2004, p. 19), entre os autores, dialoga com Munanga (2000) e Conduru (2007). Nesse contexto, os artistas afro-brasileiros "abandonam o anonimato e alguns deles começam a trabalhar dentro do conceito das chamadas artes 'popular' e 'primitiva', encorajados pelo movimento modernista e pela busca do nacionalismo" (MUNANGA, 2000, p. 105). Assim, as questões colocadas por Conduru (2007) são fundamentais, por provocarem uma discussão primordial em relação às ideias que se tem sobre a arte afro-brasileira.

Dessa forma, faz-se necessário (re)pensar o ensino de Arte Visuais, com uma proposta pedagógica em que os alunos possam ser envolvidos no processo de ensino e aprendizagem de forma dialógica e interativa, promovendo a criatividade, a compreensão e criticidade sobre a forma de ler, contextualizar e produzir a arte local e global. Ver para além do texto imagético, desconstruir e criticar estratégias de convencimento e supervalorização da cultura eurocêntrica, em detrimento da cultura de outros povos como a afro-brasileira.

A autora Thomas (2017), em seu trabalho A Arte indígena sob o olhar multiculturalista no livro didático "Arte em Interação", aborda a diversidade cultural, a partir do índio no livro didático. A metodologia é de cunho qualitativo, com estudo bibliográfico, os autores: Pierucci (1999), Candau (2008), Bonin, Ripoll e Aguiar (2015) e documentos como a Lei no $11.645 / 2008$. Como conclusão, a arte vem sendo representada hegemonicamente a partir do conceito geral de arte oriundo da cultura ocidental, a imagem do índio ainda é reproduzida de forma estereotipadas. 
É preciso caminhar na contramão do modelo balizador de imposto pelas amarras do processo colonizador, reconhecendo e valorizando cada vez mais a relevância da cultura indígena, e do povo da diáspora, celebrando as manifestações culturais e religiosas desses povos, nivelando em igual valor as culturas enredadas nas manifestações dos afrobrasileiros indígenas (BARBOSA, 2009). Nessa visão de valorização das culturas, nos remetemos a marujada bragantina, que desvela sentidos e significados das coisas, das imagens, dos elementos simbólicos que, compondo um conjunto de elementos visuais harmônicos, estão presente no cortejo e distribuído esteticamente em toda a cidade durante o período da festividade. Assim, a cidade de Bragança se reveste de um manto colorido harmônico envolvendo a todas as pessoas, inclusive os jovens bragantinos.

A pesquisa das autoras Vasconcelos, França e Pires (2018), Conexões afroamazônidas - arte e culturas híbridas, diálogos interculturais, metodologicamente, é um estudo de cunho qualitativo que se divide em duas etapas: a primeira, de enfoque bibliográfico; e a segunda, a pesquisa de campo. Tem como principais referenciais: Hall (2003), discutindo identidade cultural; Canclini (1999) e seu conceito de culturas híbridas; interculturalidade a partir de Candau (2009) e Richter (2003); e Conduru (2012) e Silva (2009), para analisar a arte afro-brasileira e afroamazônica. Como resultados, as autoras afirmam que, em resposta ao questionamento inicial, é possível promover uma identidade intercultural no aluno amazônida, por meio da abordagem de imagens e obras de arte que mostrem o negro e sua cultura de forma positivada, promovendo diálogos reflexivos sobre as contribuições desses sujeitos na construção da história e cultura da Amazônia, bem como dando visibilidade aos padrões estéticos afro-amazônidas.

Nos instigou mapear as pesquisas desenvolvida nos últimos anos para desvelarmos as pesquisas sobre a cultura visual, o ensino de artes visuais e a diversidade. A Arte pode contribuir para trazer à tona os sentidos e decifrar o espaço cultural do aluno (BARBOSA, 2009). Ratifica-se essa afirmação com a Lei de Diretrizes e Bases $n^{\circ}$ 9.394, promulgada em 20/12/1996, no seu art. 26, $\S 2$, afirma: "o ensino de Arte constituirá componente curricular obrigatório, nos diversos níveis da educação básica, de forma a promover o desenvolvimento cultural dos alunos". Desse modo, o ensino de Arte contribui para subverter a lógica de um currículo que tacitamente tenta ensinar aos jovens do Ensino Médio, bem como em outros níveis de ensino, normas e valores que comumente estão relacionados à cultura dominante.

No Brasil, desde o período colonial, foi engendrado projeto de perpetuação do poder e domínio europeu sobre os colonizados na formação da sociedade brasileira. O reconhecimento e a valorização das manifestações culturais que envolve a história e cultura afro-brasileira e africana, historicamente, esteve ausente da formação de professores e do currículo escolar, usualmente centrado em uma perspectiva do colonizador.

É necessário lutar contra a colonialidade a partir das pessoas, de suas práticas sociais, culturais, epistêmicas e políticas (WALS, 2005), numa perspectiva artística-cultural de enfrentamento à luta contra a não-existência do ser, de modo a visibilizar a construção de outros modos de viver, de poder e de saber dos negros, desvelando a verdadeira história desses povos no Brasil e a riqueza do legado das suas práticas culturais.

Segundo Barbosa (2002, p. 17-18), não podemos entender cultura de um país sem conhecer sua Arte. Para ela, a "[...] Arte como uma linguagem aguçadora dos sentidos transmite significados que não podem ser transmitidos por intermédio de nenhum outro tipo de linguagem, tais como a discursiva e a científica". Corrobora que dentre as artes, "[...] as visuais, tendo a imagem como matéria-prima, torna possível a visualização de quem somos, onde estamos e como sentimos", para além dos guetos culturais.

A cultura visual, presente na festa da marujada, possibilitou compreender os sentidos e significados das práticas culturais de jovens bragantinos. A imagem do "santo preto" remete alguns dos jovens observados a seus valores religiosos e ao valor identitário de suas ancestralidades, mas será que seus reflexos fazem parte da cultura da escola por meio da leitura/imagem. Este último possibilita refletir sobre as características de vida próprias, seus ritmos e seus ritos, sua linguagem, seu imaginário, seus modos próprios de regulação e transgressão, seu ritmo próprio de produção e de gestão de símbolos culturais (FORQUIN, 1993). 
Para outro grupo de jovens, a partir da festa da marujada em Bragança, percebemos empiricamente a importância do acesso aos códigos da cultura local, pois no momento da festividade erudito e popular se encontram em um movimento de manifestação cultural expressado pela cultura visual a partir de seus elementos visuais artísticos (imagens, danças, instrumentos, indumentárias, arquiteturas, esculturas, pinturas).

A marujada bragantina, nessa visão empírica, desvela sentidos e significados das coisas, das imagens, dos elementos simbólicos que se misturam, compondo um conjunto de elementos visuais presente no cortejo e distribuído esteticamente em toda a cidade durante o período da festividade da Marujada. Assim, a cidade de Bragança se reveste de um manto colorido harmônico envolvendo a todas as pessoas, inclusive os jovens bragantinos.

Os sentidos e significados da juventude bragantina sobre as práticas culturais da festa da marujada, a partir da cultura visual, pode revelar o grau de relação e importância da juventude com a cultura e sua identidade. De acordo com Zanella (1999), "todo indivíduo enquanto ser social insere-se, desde o momento em que nasce, em um contexto cultural, apropriando-se dele e modificando-o ativamente, ao mesmo tempo em que é por ele modificado..." (p. 153).

O trabalho com o Ensino de Arte, na ação do ensinar, promove o cruzamento de culturas e saberes, possibilita aos alunos o acesso e a interação com as distintas manifestações culturais populares presentes na sua comunidade (BRASIL, 2018). A Marujada, enquanto herança cultural africana de dimensão social, cultural, simbólica e econômica, contribui para o pertencimento cultural de jovens bragantinos a partir da escola, de seus professores e de seu currículo, sobretudo de Artes Visuais.

Martins (2007, p. 26), infere que a cultura visual busca "[...] compreender o papel social da imagem na vida da cultura". Assim, a pesquisa analisa, na segunda fase, como a cultura visual presente na manifestação cultural da marujada de Bragança adentra no currículo escolar do Ensino de Arte, por meio da cultura da escola; e que relações e valorizações a juventude faz do conhecimento da cultura visual e a apropriação do seu patrimônio cultural, considerando que são fatores indispensáveis no processo de preservação sustentável desses bens culturais, assim como no fortalecimento dos sentimentos de identidade e cidadania da juventude.

\section{BREVES CONSIDERAÇÕES}

Este estudo objetivou mapear as produções acadêmicas sobre cultura visual, ensino de Artes Visuais e diversidade cultural, produzidas em Artes nas universidades federais e nos periódicos, no período de 2014-2018. A pesquisa faz a conexão entre o ensino de artes visuais e a cultura visual, já que ambas têm a imagem como matéria prima, assim poderá subsidiar outras futuras pesquisas com relação as artes visuais e cultura visual; cultura da escola e a marujada. Os resultados acerca da cultura visual, presente na marujada bragantina, se introduzida na cultura da escola, por meio do currículo de Artes Visuais, no campo social e político, e poderá contribuir com indicativos de pauta para políticas que favoreça a juventude e a educação pública, a partir dos significados das representações culturais para a juventude sobre a cultura visual da marujada bragantina.

Vários estudos elencados se convergem ou estão em consonância com o objeto deste estudo que tem a cultura visual presente na marujada bragantina como mote. A Marujada foi declarada patrimônio Cultural e Artístico do Estado do Pará, desde 2009 e possui uma estrutura hierarquizada, tem símbolos próprios que a representam como os trajes, os chapéus das Marujas e dos Marujos, têm grande valor simbólico, comparado a coroa, ninguém pode ficar no salão sem o seu na cabeça, e as representações das fitas, cada uma cor com o seu significado, os estandartes. Essa riqueza de "coisas" elementos visuais da marujada bragantina, nos despertou o interesse em analisar pesquisas que tratassem de cultura visual, ensino de arte e práticas culturais, o objeto deste estudo.

Identificamos com o inventariado que o descritor cultura visual também chamada por estudos visuais é um campo de estudos referente à construção do visual na arte, nas mídias e na vida cotidiana, tendo a imagem como objeto central e por meio da qual são produzidos sentidos e significados em contextos culturais, muito usado por pesquisadores para discutir diversos temas como a identidade homossexual e a cultura afro- 
brasileira. Para Hernández, olhar cultura visual de dentro é:

[...] ajudar a compreender a realidade a continuar o processo de examinar os fenômenos que nos rodeiam de uma maneira questionadora e construir "visões" e "versões" alternativas não só diante das experiências cotidianas, mas também diante dos outros problemas e realidades distanciadas no tempo e no espaço do nosso. (Hernández, 2000, p. 32).

Como considerações, não temos a pretensão de esgotar o assunto, e nem cabe aqui, mas o construído, até aqui, pode servir de recurso didático para o campo da pesquisa. Concluímos afirmando a possibilidade de tensionamento das relações escolares, entre professor e aluno; ratifica-se a importância da arte na escola para a quebra de paradigmas, todos devem ter acesso à arte, e não apenas a um grupo dominante. Verificamos, empiricamente, que a juventude bragantina participa com grande interesse $e$ compromisso das celebrações da marujada. A celebração os remete às homenagens ao divino "O Santo Preto", tem grande significado religioso para a juventude., a produção visual da cultura popular de matriz africana.

\section{NOTAS}

1. Este estudo é um recorte do projeto de pesquisa de doutorado aprovado no segundo semestre em 2019 pelo Programa de Pós-Graduação de ArtesPPGARTES da Universidade Federal do Pará.

2. As teses, dissertações e artigos da ANPAP e CONFAEB serão citados de acordo com a necessidade de serem referendados no corpo do texto.

3. Bragança é uma cidade do Estado do Pará, situada na zona do salgado. Os habitantes se chamam bragantinos. O município se estende por $2.091,9 \mathrm{~km}^{2}$ e contava com 113.227 habitantes no último censo. A densidade demográfica é de 54,1 habitantes por $\mathrm{km}^{2}$ no território do município.Situado a 34 metros de altitude, de Bragança tem as seguintes coordenadas geográficas: Latitude: $1^{\circ} 3^{\prime} 57^{\prime \prime}$ Sul, Longitude: $46^{\circ}$ 47 '22" Oeste. https://www.cidade-brasil.com.br/ municipio-braganca.html. Acesso em: mar. 2019.

4. Na Festa de São Bendito, o destaque para as personagens da Capitoa e das Marujas. A Capitoa exerce papel fundamental na organização e realização deste ritual.

\section{REFERÊNCIAS}

BARBosA, Ana Mae. As Mutações do Conceito e da Prática. In: BARBosA, Ana Mae. (Org.). Inquietações e Mudanças no Ensino da Arte. São Paulo: Cortez, 2002.

BARBOSA, Ana Mae. A Imagem no Ensino de Arte: anos 1980 e novos tempos. - São Paulo: Perspectiva, 2009.

BRASIL, Base Nacional Comum Curricular. Ministério da Educação. 2017.

BRASIL. Lei n 9.394, de 20 de dezembro de 1996. Estabelece as diretrizes e bases da educação nacional. D.O.U., Brasília, 23 dez. 1996. Disponível em: <http://www.planalto. gov.br/ccivil_03/ Leis/L9394.htm>. Acesso em: 20/fev/2017.

BRASIL. Diretrizes Curriculares Nacionais da Educação Básica. Secretaria de Educação Continuada, Alfabetização, Diversidade e Inclusão. Ministério da Educação. 2013.

BRASIL. Lei Federal $\mathbf{n}^{\mathbf{0}}$ 10.639, de 09 de Janeiro de 2003. Altera a Lei n. ${ }^{9} 9.394$, de 20 de dezembro de 1996 (estabelece as diretrizes e bases da educação nacional, para incluir no currículo oficial da rede de ensino a obrigatoriedade da temática história e cultura afro-brasileira, e dá outras providências).

SILVA, A. Bordallo da. Contribuição ao estudo do folclore amazônico na zona brangantina. Boletim do Museu Paraense Emilio Goeldi (5), 1959.

BOURDIEU, Pierre. A distinção. Crítica social do julgamento. Porto Alegre: Zouk, 2007 a.

CARVALHO, Gisele Maria de Oliveira. A festa do "Santo Preto": Tradição e percepção da marujada bragantina. 2010. 166f. Dissertação (mestrado) Centro de Desenvolvimento Sustentável, Universidade de Brasília - UNB - Brasília.

CHARTIER, Roger. A história cultural. Entre práticas e representações. Lisboa: DIFEL, 1990. O mundo como representação. In: Estudos avançados, 11 (5), 1991.p. 173-191.

COELHO, Wilma de Nazaré Baía; SANTOS, Raquel Amorim dos.; SILVA, Rosângela Maria de Nazaré Barbosa e. Educação e Relações Raciais: estado da arte em programas de Pós- graduação em 
Educação (2000-2010). Revista EXITUS | Volume 04 | Número 01 | Jan/Jun. 2014. p. 111 - 141.

CORRÊA, Ester Paixão. Pérolas de Caeté: a dança das Marujas de São Benedito de Bragança-PA. Dissertação (Mestrado) - Universidade Federal do Pará, Instituto de Filosofia e Ciências Humanas, Programa de Pós-Graduação em Antropologia, Belém, 2017.

DAYRELL, J.T. A escola faz juventudes?: reflexões em torno da socialização juvenil. Educação \& Sociedade, Campinas, v. 28, n. 100 , p. $1105-$ 1128, out. 2007.

DAYRELL, J.T. et al. Juventude e escola. In: SPOSITO, M.P. 0 estado da arte sobre juventude na pós-graduação brasileira: Educação, Ciências Sociais e Serviço Social (1999-2006). Belo Horizonte: Argumentum, 2009.

DUSSEL, E. Ética da libertação: na idade da globalização e da exclusão. Petrópolis: Vozes, 2002.

FARIA, Carlos Aurélio Pimenta de. Ideias, Conhecimento e Políticas Públicas um inventário sucinto das principais vertentes analíticas recentes. Revista Brasileira de Ciências Sociais Vol. 18 No. 51. RBCS. Fevereiro/2003. p. 21-29.

FERNANDES, José Guilherme do Santos. Pés que andam, pés que dançam: Memória e identidade e região cultural na esmolação e marujada de São Benedito em Bragança (PA). Belém: Eduepa, 2011.

FORQUIN, J. Claude. Escola e Cultura: a sociologia do conhecimento escolar. Porto Alegre: Artes Médicas, 1993.

HERINGER, R. Desigualdades raciais no Brasil: síntese de indicadores e desafios no campo das políticas públicas. Cad. Saúde Pública [online], vol. 18,2002 , p. 57-65.

HERNÁNDEZ, Fernando. Cultura visual, mudança educativa e processo de trabalho. Porto Alegre: Artmed, 2000.

HERNÁNDEZ, Fernando. Catadores da Cultura Visual: transformando fragmentos em nova narrativa educacional. Porto Alegre: Mediação, 2007.

MARCONI, M. A.; LAKATOS, E. M. Técnicas de pesquisa. São Paulo: Atlas, 1988.

MARTINS, Raimundo. A cultura visual e a construção social da arte, da imagem, e das práticas do ver. In Oliveira, Marilda Oliveira de (Org). Arte, educação e cultura. Santa Maria: Editora UFSM, 2007. p. 19-40.

MORAES, Aldilene Lopes de. Imagens de Sant'Ana: história, cultura e representação na Amazônia Paraense. Dissertação de Mestrado, Programa de Pós-Graduação em Linguagens e Saberes na Amazônia, Universidade Federal do Pará, Campus de Bragança. Bragança, 2015.

MÜLLER, Tânia Mara Pedroso. As pesquisas sobre o estado do conhecimento em relações étnico-raciais. Revista do Instituto de Estudos Brasileiros, v. 62, 2015, p. 164-183.

SILVA, Dário Benedito Rodrigues Nonato da. Os Donos de São Benedito: convenções e rebeldias na luta entre o catolicismo tradicional e devocional na cultura de Bragança, século XX. Dissertação de Mestrado, História, Instituto de Filosofia e Ciências Humanas, Universidade Federal do Pará. Belém, 2006.

ROSSI, Maria Helena Wagner. Imagens que falam: leitura da arte na escola. 4. ed. rev. e atual. Porto Alegre: Mediação, 2009.

SARAmago, José. A Caverna. São Paulo: Companhia das Letras, 2000.

SCHLICHTA, Consuelo. Mundo das ideias: Arte e educação, há um lugar para Arte no Ensino Médio? Curitiba: Aymará, 2009.

ZANELLA, A. V. Aprendendo a tecer a renda que o tece: apropriação da atividade e constituição do sujeito na perspectiva histórico-cultural. Revista de Ciências Humanas, edição especial temática, 1999, p. 145-158.

ABREU, Carla de.; OSPINA, Juan; MONTELES, Nayara. Cultura Visual e Construções de Gênero: Reflexões e Experiências em sala de aula. UFG Simpósio 8 - Sobre espaços e tempo da pesquisa em educação e arte - escrita, análise e interpretação. XXV Encontro da ANPAP. Porto Alegre-RS, 2016. p. 3255-3270.

BALISCEI, João Paulo; CALSA, Geiva Carolina; STEIN Vinícius. Tiana, a primeira princesa negra de Disney: olhares analíticos construídos junto à cultura visual. VISUALIDADES, Goiânia v.15 n.2, 2017, p. 137-162, jul.

BRITO, Sislândia Maria Ferreira Abordagem Reflexiva Sobre a Cultura Visual como Expressão 
da Comunicação Contemporânea. XXIV Congresso Nacional da Federação dos Arte/Educadores do Brasil-CONFAEB. Ponta Grossa-PR, 2014. p. 760-771.

CARDOSO JUNIOR, Wilson. Ensino de Artes Visuais em Perspectiva Eurocêntrica: Um Estudo de Caso no Colégio Pedro II. 38a Reunião Nacional da ANPEd. UFMA: São Luís/MA, 2017, p. 1-15.

CERUTTI, et. al. 0 Agente Cultural: Estudos e Práticas Étnicos Culturais em Espaços Socioeducativos. 2014.

FREITAS Letícia Pereira de.; SILVA, Hertha Tatiely. Cultura Visual e Arte/Educação Baseada na Comunidade: Interlocuções com a Educação do Campo. 2018.

GOMES, Josias Marinho de Jesus. A experiência na formação de professores a partir da temática afrodescendente. 2016.

MAGALHÃES, Ana Del Tabor Vasconcelos Experiências de ensinar/aprender no contexto dos estágios em Artes Visuais. XXVI Congresso Nacional da Federação dos Arte/Educadores do Brasil. Boa Vista, novembro de 2016.

MENDES, Sonia Maria da Costa; PAZINI, Daiane; VERSOLATTO; Giovana; RUIZ, Raony Formação De Professores para o Ensino de Artes Visuais: uma Experiência de Estágio com a Fotografia Por Meio Da Leitura De Imagem. XXV Congresso Nacional da Federação dos Arte/Educadores do Brasil. Fortaleza-CE. 2015, p.1729-1744.

SILVA, Benedicta Filomena Almeida Vieira O Desafio de Ensinar Arte: Cultura Visual e Novos Olhares para o Trabalho Docente. XXV Congresso Nacional da Federação dos Arte/Educadores do Brasil. Fortaleza-CE. 2015, p. 530-543.

SILVA, Clécio Ernande Da; ARA:JO, Clarissa Martins de. OEnsino de Arte e os Saberes Escolares: A Experiência de uma Comunidade Quilombola. XXIV Congresso Nacional da Federação dos Arte/Educadores do Brasil-CONFAEB. Ponta Grossa-PR. 2014, p. 520-532.

SILVA, Dilma Oliveira da. As Práticas Educativas no Cotidiano da Marujada: uma análise epistemológica dos saberes populares e sua importância para o processo educativo. XII Congresso Nacional de Educação- EDUCERE. Pontifícia Universidade Católica do Paraná-PR, 2015.
SILVA, Marcia Inês da Silva; SILVA Elsieni Coelho da. Oficinas de Artes Para Bordar e Pensar: Interculturalidade e Identidade no Ensino de Artes Visuais, 2018.

THOMAS, Mariana Schnorr. A Arte Indígena sob o olhar Multiculturalista no Livro Didático "Arte em Interação". XXVII Congresso Nacional da Federação dos Arte/Educadores do BrasilCONFAEB, 2017, p. 1149-1169.

VASCONCELOS, Júnia de Barros Braga; FRANÇA, Rita de Cássia Cabral Rodrigues de França; PIRES, Andresa Carvalho Lopes. Conexões Afroamazônidas - Arte e Culturas Híbridas, Diálogos Interculturais. - XXX Congresso Nacional da Federação dos Arte/Educadores do BrasilCONFAEB. 2018, p. 443-455.

\section{SOBRE A AUTORA}

Rita de Cássia Cabral Rodrigues de França é doutoranda pelo Programa de Pós-Graduação em Artes-PPGARTES da UFPA. Mestra em Educação pela Universidade Federal do Pará. Licenciada em Educação Artística com habilitação em Artes Plásticas pela UFPA. É professora da Escola de Aplicação da Universidade Federal do Pará/EAUFPA. Membro do Núcleo de Estudos e Pesquisa sobre Formação de Professores e Relações Étnico-Raciais GERA/IFCH/UFPA. E-mail: rcabralfranca12@gmail.com 